\title{
EVALUAREA EFECTELOR DE PROTECȚIE A BIOSTIMULATORULUI REGLALG FAŢĀ DE DIFERIŢI AGENŢI PATOGENI PRIN COLORAREA FRUNZELOR DIFERITOR SPECII DE PLANTE CU RODAMINA 6G
}

\author{
Jelev N., Badașco S. \\ Istitutul de Genetică, Fiziologie și Protecție a Plantelor, Moldova \\ Jelevnn@yahoo.com
}

\begin{abstract}
The article presents the results demonstrating the effectiveness of the rapid method for detecting infection at the initial stages of spreading on the leaves of winter wheat and barley, apple and grape plants using 0,05\% Rodamina $6 G$ solution as an indicator for determining the degree of infection. The assessment of the degree of infection is carried out visually on a special scale. The data on the effectiveness of presowing treatment of wheat seeds in a solution of 1/200 of the biostimulator Reglalg for increasing plant resistance to diseases are presented.
\end{abstract}

Key words: biostimulator Reglalg, winter wheat, resistance, infection, Rodamina $6 G$

\section{Introducere}

La plante infecțiile se răspândesc în perioade de vegetație atunci când predomină condiții favorabile pentru înmulțirea lor. Atacul poate începe primăvara sau uneori și toamna târziu, de exemplu, pentru grâul comun de toamnă (Triticum aestivum L.). Printre speciile de 
ciuperci, care provoacă infecțiile, rugina brună este cea mai dăunătoare. Atacul acestei ciuperci la grâu provoacă deteriorarea țesuturilor frunzei și tecii, afectează productivitate și calitatea recoltei [1,2]. Infectarea plantelor în toamnă poate reduce rezistența lor la intrarea în iarnă și facilitează apariţia infecțiilor secundare cu alți patogeni. În cazul atacului în faza de înflorire productivitatea plantei scade de două ori, iar în cazul atacului în faza de lapte recolta scade cu 27-28\% [6]. Intervalul de timp de la infecție până la răspândirea bolii, la temperaturi de $10-20^{\circ} \mathrm{C}$, este de 7-10 zile. Din aceste considerente este necesară depistarea timpurie a leziunilor provocate de diferiți agenți patogeni și tratarea în fazele inițiale ale infecției cu substante de combatere.

Pentru soluționarea acestei dileme, noi ne-am propus să elaborăm o metodă simplă și efectivă pentru depistarea infecției la faza inițială de infectare a frunzelor de grâu comun de toamnă. În procesul cercetării, materialul vegetal a fost tratat cu diferiți agenți chimici: metiloranj, turnesol, fenolftaleina, roşu neutru, ninhidrina şi Rodamina 6G. Cel mai eficient dintre agenții testați a fost emulsia de Rodamina $6 G$. Ulterior metoda a fost optimizată în ceea ce priveşte componenţa emulsiei şi determinarea timpului optimal de imersare a frunzelor în soluţie de Tris cu concentraţie specifică şi emulsie de colorare. Metoda dă posibilitatea de a prezice perioada de infecție a bolilor fungice (rugina la mere şi pere, mucegai de struguri, rugina la cereale) ale culturilor agricole cu câteva zile înainte de apariţia simptomelor vizibile şi face posibilă aplicarea în prealabil a măsurilor de protecție a plantelor.

\section{Materiale și metode}

În cercetări au fost utilizate frunzele a diferitor specii de plante: orz, grâu comun de toamnă s. Moldova 5, măr și vița de vie, prelevate de pe câmpul experimental al Institutului de Genetică, Fiziologie şi Protecţie a Plantelor, cu diferit nivel de afectare: vizual neafectate, mediu și puternic afectate. Probele de frunze de la plantele de orz și grâu comun au fost selectate la diferite etape de dezvoltare (faza de înfrățire, de burduf, înflorire, maturitate în lapte și maturitate în ceară a boabelor) și de la toate nodurile începând de la nodul de înfrățire până la frunza stindard. Frunzele proaspăt prelevate au fost fotografiate fiind fixate între plăci de sticlă, apoi imersate în emulsie de Rodamină $6 G$ în concentrație de $0,05 \%$ pe durata de 20min, ulterior după colorare frunzele au fost amplasate între plăci de sticlă şi iarăşi fotografiate.

Pentru aprecierea vizuală a gradului de atac a plantelor s-a utilizat scala (Fig. 1) și fotografiile frunzelor. Evaluarea gradului de atac a fost efectuată pe partea superioară și partea inferioară a frunzei.

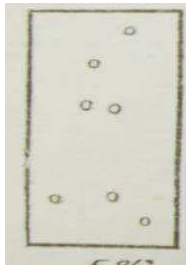

$5 \%$

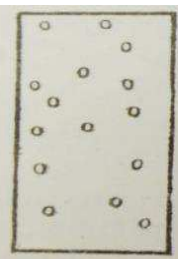

$10 \%$

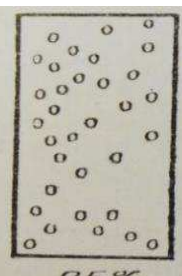

$23 \%$

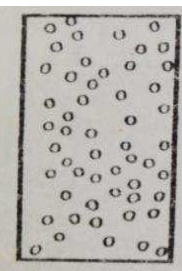

$40 \%$

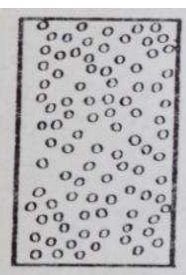

$65 \%$

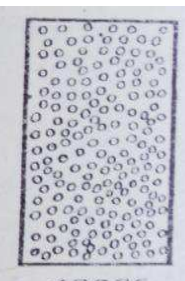

$100 \%$

Figura 1. Scala de determinare a gradului de infectare a plantelor cu rugina brună pe frunze [3].

Evidențierea gradului de atac la frunzele de măr și viței de vie este posibilă prin preimersarea în soluție de $0,6 \mathrm{M}$ Tris $\mathrm{Cl}$ pe parcursul a 15 min şi apoi imersarea în emulsie de Rodamină $6 G 30 \mathrm{~min}$. 
Pentru protecția genotipurilor de grâu de infecții în condiții de câmp înainte de semănat semințele au fost tratate cu soluția biostimulatorului Reglalg diluat cu apă în raport de $1 / 200$.

\section{Rezultate și discuții}

Din Figurile 2, 3, şi 4 se poate observa, că pe frunzele tratate cu emulsie de Rodamină $6 G$ în conformitate cu metoda, este mult mai eficient să se efectueze o evaluare vizuală fiabilă a gradului de infecție a plantelor. Conform figurei 2 , rezultă că fără tratamentul frunzelor cu o soluție de Rodamină $6 G$, este imposibil să se determine vizual prezența infecției într-un stadiu incipient pentru genotipurile de orz cu grad scăzut și mediu de infecție a frunzelor. Același rezultat a fost observat şi pentru alte specii de plante studiate.

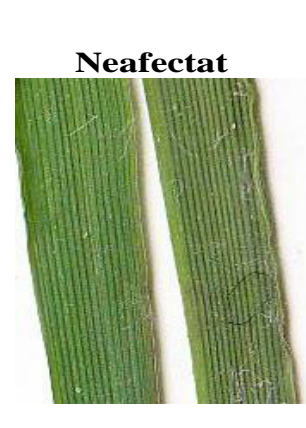

\section{Partea superioară a frunzei}
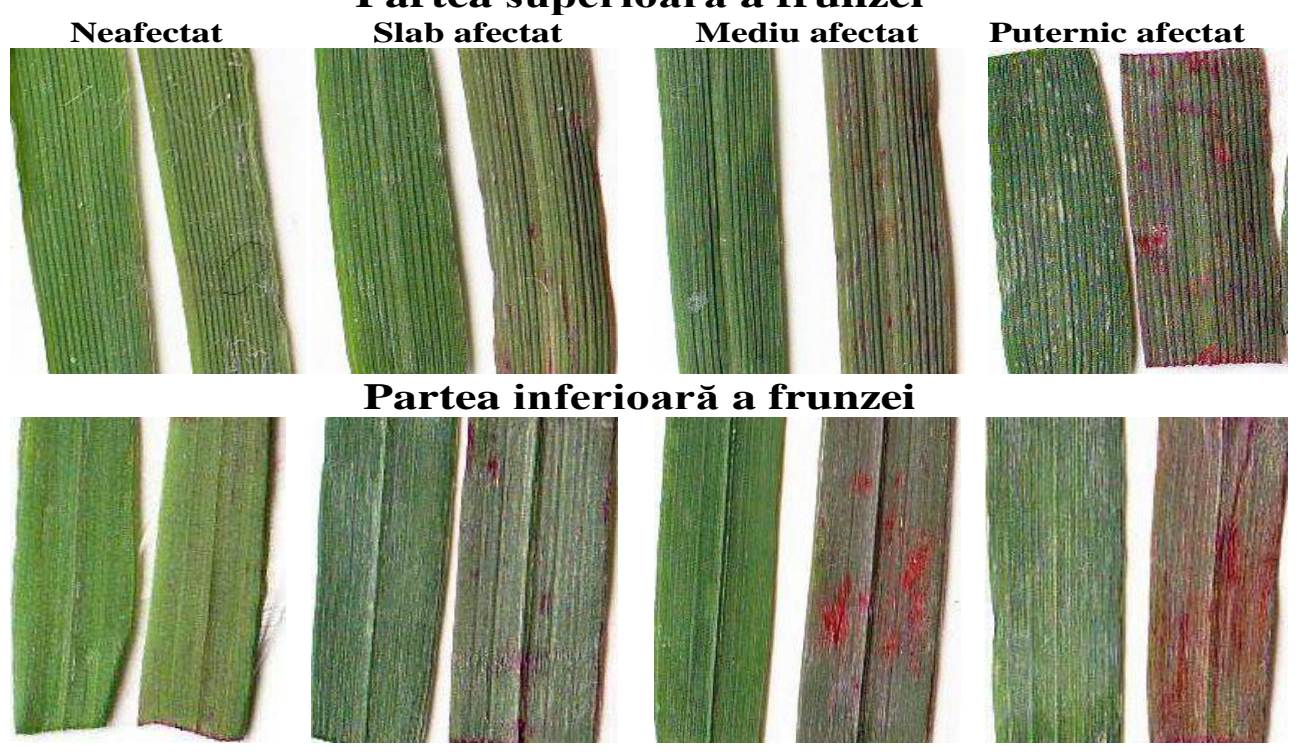

Figura 2. Pe imagine sunt prezentate secțiuni din frunze de orz cu diferit grad de afectare, colectate de pe lotul experimental al Institutului de Genetică, Fiziologie şi Protecție a Plantelor pe data de 10-12-2015. La stânga sunt prezentate frunzele martor - necolorate, iar spre dreapta - frunzele colorate cu emulsie de Rodamina $6 G$.

Analizând imaginile din figura 3, putem concluziona că gradul de infecție a frunzelor plantelor martor, netratate cu o soluție de Rodamina $6 G$, este de numai $10-25 \%$, în timp ce valoarea sa reală este de $40-65 \%$, vizibilă după tratamentul acelorași frunze cu soluția de Rodamina $6 G$.

Pentru plantele experimentale, ale căror semințe înainte de semănat au fost tratate cu biostimulatorul Reglalg aceste valori sunt egale cu 0-5\% (fără tratamentul frunzelor cu soluție de Rodamina 6G) şi 10-25\% (după tratamentul frunzelor cu soluție de Rodamina 6G).

Datele din figura 3 demonstrează că gradul de infectare a plantelor experimentale este mult mai mic decât a celor martor. Această legitate se respectă la etape diferite de dezvoltare a plantelor de grâu, (datele sunt incluse în tabel). Aceste date demonstrează eficiența utilizării biostimulatorului Reglalg pentru protejarea plantelor de infecții. Această proprietate a Reglalgului este confirmată și în fotografiile incluse în figura 4. 


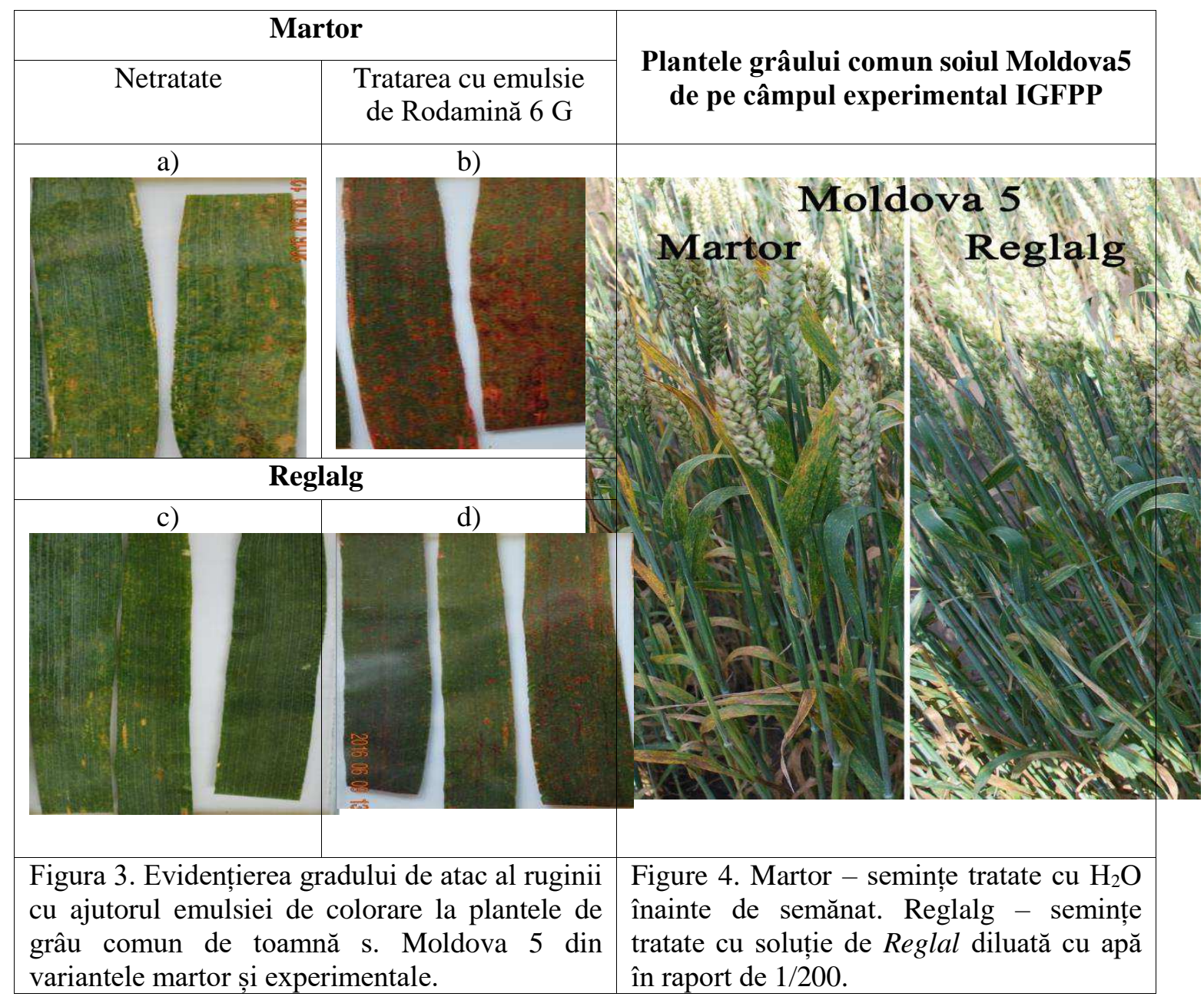

Tabel. Rata plantelor soiului de grâu Moldova 5 atacate cu rugină la diferite etape de dezvoltare.

\begin{tabular}{|c|c|c|c|c|}
\hline \multirow{2}{*}{ Varianta } & \multicolumn{4}{|c|}{ Fazele de dezvoltare } \\
\cline { 2 - 5 } & Înspicare & Înflorire & $\begin{array}{c}\text { Maturitate în lapte } \\
\text { a boabelor }\end{array}$ & $\begin{array}{c}\text { Maturitate în ceară } \\
\text { a boabelor }\end{array}$ \\
\hline Martor & $25 \pm 5,0$ & $35 \pm 3,6$ & $55 \pm 7,0$ & $65 \pm 6,0$ \\
\hline Reglalg & $10 \pm 4,0$ & $15 \pm 2,0$ & $25 \pm 5,0$ & $30 \pm 4,5$ \\
\hline
\end{tabular}

Metoda elaborată a fost confirmată și la frunzele de măr și viță de vie (Fig. 5). 


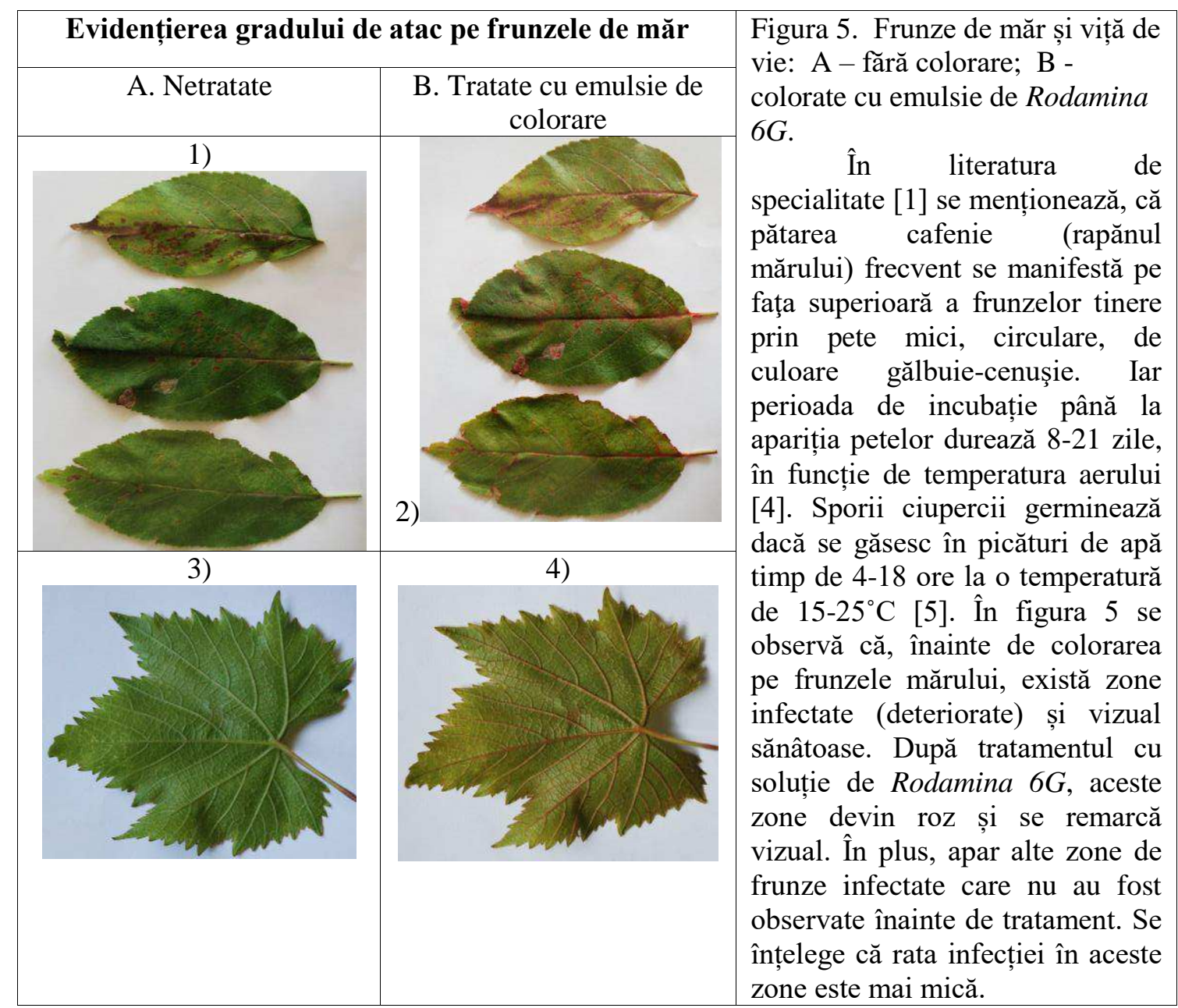

\section{Concluzii}

1. Metoda expres elaborată de noi dă posibilitate de a detecta atacul diferitor plante cu agenţi patogeni înainte ca simptomele infectării să se manifeste în mod vizibil (ocular).

2. Biostimulatorul Reglalg sporește rezistenţa plantelor faţă de atacul agenţilor patogeni.

\section{Bibliografie}

1. Bădărău, S., Gaibu, Z. Bolile plantelor cultivate în Republica Moldova. Partea I. Micoze. Chișinău, Tipo Print Caro, 2009, 355 p.

2. Lazari I., Bădărău S., Boli infecţioase ale culturilor agricole în Republica Moldova. Chişinău: Cuant, 1999. P. 352

3. Пруцков Ф. И. Озимая пшеница. Москва: Колос, 1976, 352c.

4. Lefter Gh., Minoiu N. Combaterea bolilor şi dăunătorilor speciilor pomicole sămânţoase. Bucureşti. Ceres, 1990. P. 257.

5. Iacob Viorica. Bolile plantelor cultivate - prevenire şi combatere. Iaşi. Ed. Alfa, 2010. P. 255-258.

6. Хазанов Б.А. Ржавчины болезни пшеницы в Узбекистане и борьба с ними. Ташкент 2007. 94 c. 